http://dx.doi.org/10.30681/23588403v12i033851

\title{
VARIAÇÃO E ESTILO LINGUÍSTICO EM LETRA DE CANÇÃO: BREVE PERSPECTIVA PARA O ENSINO DE LÍNGUA MATERNA
}

\author{
Maria Lidiane de Sousa PEREIRA (UECE) ${ }^{1}$ \\ Data de recebimento: 06/03/2019 \\ Aceite: 02/06/2019
}

\begin{abstract}
Resumo: Neste artigo, discutimos o modo como certos fenômenos de variação linguística podem funcionar enquanto recurso estilístico na letra da canção $A$ volta da Asa branca, interpretada por Luiz Gonzaga. De igual modo, apresentamos algumas breves propostas para o tratamento da variação linguística enquanto recurso estilístico durante o ensino de língua materna. Os dados são analisados e as reflexões são tecidas à luz de estudos vinculados à Estilística descritiva. Em linhas gerais, localizamos, dentre outros, fenômenos variáveis como iotização, rotacismo, variação na concordância nominal. Compreendemos que esses fenômenos são postos na letra da canção $A$ volta da Asa branca não apenas para realçar o caráter heterogêneo do Português Brasileiro, mas também com o propósito de evocar (ainda que não de modo fiel) traços da linguagem falada por sujeitos com pouca escolaridade e oriundos do interior do sertão brasileiro. De igual maneira, compreendemos que a ênfase em determinadas variedades linguísticas é realizada com o intuito de realçar o sentimento de pertencimento à terra natal. Somados, acreditamos que esses pontos podem ser, portanto, tidos como recursos estilísticos usados em A volta da Asa branca para realçar a expressividade linguística da canção. Diante disso, argumentamos que o trabalho com letras de canções, como A volta da Asa branca, constitui uma ferramenta didática importante para o ensino de língua materna, pois pode promover, dentre os coisas, a ideia de que fenômenos de variação linguística podem funcionar como importante recurso estilístico em determinados gêneros textuais e proporcionar uma compreensão mais produtiva acerca do funcionamento da linguagem.
\end{abstract}

Palavras-chave: Variação linguística. Estilo linguístico. Letra de canção. Ensino de Língua Materna.

\begin{abstract}
In this article, we discuss how certain phenomena of linguistic variation can function as a stylistic resource in the lyrics of the song A volta da Asa branca, played by Luiz Gonzaga. Likewise, we present some brief proposals for the treatment of linguistic variation as a stylistic resource during mother tongue teaching. The data are analyzed and the reflections are woven in the light of studies related to Descriptive stylistics. In general terms, we find, among others, variable phenomena such as iotization, rotation, variation in nominal agreement. We understand that these phenomena are put in the lyrics of the song A volta da Asa bbranca not only to highlight the heterogeneous character of Brazilian Portuguese, but also with the purpose of evoking (although not in a faithful way) traces of the language spoken by subjects with little schooling and coming from the interior of the Brazilian backlands. In the same way, we understand that the emphasis on certain linguistic varieties is carried out with the intention of enhancing the feeling of belonging to the native land. Added, we believe that these points can therefore be regarded as stylistic resources used in A volta da Asa branca turn to enhance the linguistic expressiveness of the song. In this regard, we argue that working with song lyrics, such as $A$ volta da Asa branca, is an important didactic tool for mother tongue teaching, since it can promote, among other things, the idea that linguistic variation phenomena can function as an important stylistic resource in certain textual genres and to provide a more productive understanding of the functioning of language.
\end{abstract}

Keywords: Linguistic variation. Language style. Song lyrics. Teaching of Mother Tongue.

\section{Introdução}

\footnotetext{
${ }^{1}$ Mestre em Linguística Aplicada pelo Programa de Pós-Graduação em Linguística Aplicada (PosLA) da Universidade Estadual do Ceará (UECE). Graduada em Letras pela Universidade Regional do Cariri (URCA). Atualmente, é doutoranda em Linguística Aplicada pelo PosLA/UECE.
} 
Nos últimos anos, desenvolvemos alguns trabalhos à luz dos postulados da Estilística descritiva (PEREIRA; XAVIER; GRANGEIRO, 2013; GONÇALVE; SANTOS; PEREIRA, 2016; GOMES; LUCENA; PEREIRA, 2016; PEREIRA; ARAÚJO; PEREIRA, 2016; PEREIRA et al., 2017a; PEREIRA et al., 2017b). Em linhas gerais, com tais estudos, procuramos analisar diferentes fenômenos estilísticos presentes no gênero letra de canção². Ainda que durante a realização desses trabalhos não tenhamos abordado fenômenos estilísticos em consonância com o ensino de língua materna - em nosso caso específico, a língua Portuguesa do Brasil - foi possível identificar algumas possibilidades para a abordagem dessa temática.

$\mathrm{Na}$ verdade, sabemos que a necessidade de tratar questões estilísticas durante o trabalho com a língua em sala de aula é apontada por muitos estudiosos, dentre os quais vale destacar o linguista francês Charles Bally - precursor dos estudos estilísticos no cenário da linguística moderna. De acordo com Bally (1951), o estudo da língua desenvolvido apenas com base nas chamadas gramáticas normativas, bem como nos textos literários proporciona uma visão parcial da língua.

Assim, um trabalho realmente produtivo $^{3}$ com a língua em sala de aula precisa assegurar o estudo dos usos reais que fazemos desse tão complexo e fascinante fenômeno que é a linguagem verbal. Esse fato, por sua vez, só é possível quando consideramos os mais diferentes gêneros textuais e não apenas os literários (MARTINS, 2000). Afinal, é por meio dos diversos gêneros que podemos perceber, dentre muitas outras coisas, o uso efetivo da língua nas mais diferentes esferas da sociedade (MARCUSCHI, 2008).

Ainda que afirmações como essas possam soar como um truísmo, nos dias de hoje, concordamos com Callou e Leite (2009) e Romualdo (2011) quando dizem que a abordagem estilística da língua, por exemplo, ainda não recebeu a devida atenção em sala de aula. Diante disso, este artigo intenciona abordar, ainda que brevemente, algumas possibilidades de

\footnotetext{
${ }^{2}$ De acordo com Costa (2010, p. 118, grifo no original), “canção é um gênero híbrido, de caráter intersemiótico, pois é resultado da conjugação de dois tipos de linguagens, a verbal e a musical (ritmo e melodia)". Ainda que esse mesmo autor aponte a necessidade de abordar as dimensões verbal e musical juntas, sob pena de confundir a canção com o gênero letra de canção, assinalamos que não faremos aqui considerações acerca de questões melódicas das canções selecionadas. Afinal, interessa-nos observar questões de variação e estilo presentes na linguagem verbal em si, ou seja, na letra da canção selecionada.

${ }^{3}$ Na compreensão de Travaglia (2009), o ensino produtivo visa, sobretudo, o aprimoramento da capacidade de os estudantes compreenderem e produzirem os mais variados gêneros textuais, nas mais diversas situações de interação comunicativa. Par isso, o trabalho com a língua em sala não deve buscar "alterar padrões que o aluno já adquiriu, mas aumentar os recursos que possui e fazer isso de modo tal que tenha a seu dispor, para uso adequado, a maior escala possível de potencialidades de sua língua em todas as diversas situações em que tem necessidade delas" (TRAVAGLIA, 2009, p.40).
} 
tratamento dos diferentes fenômenos de variação linguística e seu funcionamento enquanto recurso estilístico a partir do gênero letra de canção, no contexto escolar.

Importante destacar que as reflexões tecidas aqui foram construídas a partir dos postulados teóricos de estudiosos como Bally (1951), Martins (2000) e Monteiro (2012). No que concerne à demonstração de algumas possibilidades de análise da variação linguística enquanto recurso estilístico, selecionamos a letra da canção A volta da Asa branca ${ }^{4}$ (GONZAGA; DANTAS, 2001), interpretada pelo cantor e compositor brasileiro Luiz Gonzaga, conhecido também como o Rei do Baião.

Haja vista uma melhor abordagem e distribuição dos conteúdos programados para este artigo, dividimos este texto em três seções, além desta introdução. Assim, na seção $2 \mathrm{~A}$ estilística e o fenômeno do estilo linguístico: um pouco de teoria, comentamos alguns dos principais aspectos teóricos que assinalam a compreensão do fenômeno do estilo no âmbito da Estilística descritiva. Já na seção 3 A estilosa Volta Asa Branca e o ensino de língua materna, analisamos o potencial estilístico de alguns fenômenos de variação linguística na letra da canção A volta da Asa branca e refletimos sobre algumas possibilidades de abordagem das questões analisadas no contexto do ensino de língua materna.

\section{A Estilística e o fenômeno do estilo linguístico: um pouco de teoria}

Desde que se firmou enquanto área de estudos da linguagem, a Estilística vem sendo compreendida como a ciência que observa o fenômeno do estilo linguístico. Essa delimitação e consequente conceituação passaram a ser amplamente aceitas diante do êxito obtido pelos trabalhos de Bally (1951), desenvolvidos a partir da década de 1950. Afinal, foi Bally (1951) quem conseguiu delimitar com precisão os interesses e métodos da Estilística, mais precisamente, a Estilística de linha descritiva.

Na compreensão de Bally (1951, p.16), a Estilística pode ser entendida como a área que compreende o "estudo da expressão dos fatos da língua, organizados a partir do conteúdo emocional, isto é, a expressão de fatos da sensibilidade da linguagem e da ação dos fatos da

\footnotetext{
${ }^{4}$ A escolha dessa canção justifica-se porque, mesmo a partir de análises superficiais, é possível identificar uma série de fenômenos de variação linguística que, como buscamos mostrar, neste capítulo, podem funcionar como recursos estilísticos. Além disso, pontuamos que a letra dessa mesma canção foi alvo de nosso interesse em outro trabalho (Cf. Pereira, Araújo e Pereira, 2017). Todavia, no referido trabalho, não refletimos sobre algumas possibilidades de abordagem da potencialidade estilística dos fenômenos de variação presentes na letra da canção Asa branca. Esse fato, para nós, justifica a retomada da canção, neste capítulo.
} 
língua sobre a sensibilidade" ${ }^{\circ}$. Ou seja, para o estudioso francês, interessa à Estilística descritiva observar como determinados elementos linguísticos são usados com o intuito de expressar não apenas conteúdos linguísticos ou lógicos, mas também o modo como esses elementos realçam determinadas mensagens, exprimem sentimentos, constroem os mais diferentes sentidos e, assim, assinalam o estilo dos mais diversos enunciados.

Não obstante, sabemos que mesmo em face dessa clara e precisa delimitação da Estilística enquanto área do conhecimento, a compreensão do seu objeto de estudo, isto é, o estilo, é uma questão de grande complexidade. Não à toa, a delimitação do fenômeno do estilo linguístico vem, há décadas, movendo o interesse e dividindo a opinião de diversos estudiosos. Como consequência, sabemos que é possível encontrar hoje uma ampla gama de acepções para o fenômeno do estilo (CRYSTAL; DAVY, 1969; ENKVIST; SPENCER; GREGORY, 1974; LAPA, 1988; MARTINS, 2000).

Desse modo, frisamos que, aqui, o estilo é pensado como um fenômeno resultante da interação entre elementos afetivos por meio dos quais é possível expressar, em parte, o ego e, em parte, as forças sociais as quais está submetido o falante/escrevente (BALLY, 1941, 1951). Sobre essa ideia de estilo, é importante destacar que ela só é possível a partir da compreensão de língua enquanto um fenômeno heterogêneo.

Assumir a heterogeneidade como uma das mais marcantes propriedades das línguas naturais, implica reconhecer, antes de tudo, que ao fazer uso da língua, temos à nossa disposição não apenas o modelo de língua tido como padrão ${ }^{6}$, mas também uma série de variedades linguísticas que são usadas em conformidade com nossos propósitos comunicativos, identidades sociais, o público para o qual falamos ou escrevemos, os interesses que acreditamos ter nosso público, dentre muitos outros fatores (BALLY, 1951; CRYSTAL; DAVY, 1969; MARTINS, 2000). Tais usos, vale ressaltar, nem sempre condizem com o padrão de língua imposto pela tradição normativa.

A partir do princípio da heterogeneidade linguística, Monteiro (2012) explica que a 'fuga da norma' ou 'desvio' pode ser apontada como uma das mais produtivas formas de construção do estilo linguístico, em diversos gêneros textuais. Sobre essa questão, são dignas de ressalto, as palavras de Monteiro (2012, p.59):

\footnotetext{
5 "Étude des faits d'expression du language organizé du point de vue de leur contenu affective, cest-à-dire l'expression des faits de la sensibilité par le language et l'action des faits de language sur la sensibilité" (BALLY, 1951, p.16, tradução nossa).

${ }^{6}$ Haja vista a polissemia do termo 'padrão' ou 'norma padrão', nos estudos da linguagem, pontuamos que, aqui, a expressão 'norma padrão' é usado para referir o modelo de língua apregoado pelas gramáticas tradicionais ou normativas - ainda muito usadas em sala de aula (MONTEIRO, 2012; FARACO; ZILLES, 2017).
} 
Para comunicar os conteúdos provenientes da sensibilidade, o falante ou escritor, se conhece a norma, tem duas opções: ou a respeita, ou deliberadamente decide transgredi-la e ultrapassá-la, aproveitando as possibilidades que o sistema põe à sua disposição. A criatividade então se manifesta, com tudo o que dela deriva: o estranhamento, o prazer estético, multivalência significativa.

Diante disso, é importante ressaltar também que, conforme vemos sinalizando, interessa à Estilística descritiva os enunciados que apresentam finalidades estéticas fato que justifica a compreensão de desvio como oposição ao uso da norma padrão da língua. Entretanto, é salutar dizer que só é considerado estilístico o desvio proposital e que resulta em efeito expressivo. Logo, quando os desvios derivam de possíveis lapsos eventuais ou inabilidade com o processo de criação dos enunciados (orais ou escritos), não há, no geral, aspectos estilísticos a considerar.

\section{A estilosa Volta da Asa branca e o ensino de língua materna}

Conforme destacamos de início, nesta seção, colocamos em discussão, a potencialidade estilística de alguns fenômenos de variação presentes na letra da canção $A$ volta da Asa branca, interpretada por Luiz Gonzaga. De igual modo, procuramos destacar a possibilidade e relevância de abordar alguns dos recursos estilísticos presentes na letra da canção em foco no trabalho com a língua materna em sala de aula, a partir da exploração do gênero letra de canção. Dito isto, vejamos, na íntegra, a letra da canção A volta da Asa branca:

\section{A volta da Asa branca}

(01) Já faz três noites

(02) Que pro norte relampeia

(03) A Asa branca

(04) Ouvindo o ronco do trovão

(05) Já bateu asas

(06) E vortou pro meu sertão

(07) $\mathrm{Ai}$, ai eu vou me embora

(08) Vou cuidar da prantação

(09) A seca fez eu desertar da minha terra

(10) Mas felizmente Deus agora se alembrou

(11) De mandar chuva 
(12) Pr'esse sertão sofredor

(13) Sertão das muié séria

(14) Dos home trabaiado

(15) Rios correndo

(16) As cachoeira tão zoando

(17) Terra moiada

(18) Mato verde, que riqueza

(19) E a Asa branca

(20) Tarde canta, que beleza

(21) Ai, ai, o povo alegre

(22) Mais alegre a natureza

(23) Sentindo a chuva

(24) Eu me arrescordo de Rosinha

(25) A linda flor

(26) Do meu sertão pernambucano

(27) E se a safra

(28) Não atrapaiá meus pranos

(29) Que que há, o seu vigário

(30) Vou casar no fim do ano

Fonte: (GONZAGA; DANTAS, 2001).

Dentre os muitos fenômenos variáveis presentes na letra da canção A volta da Asa branca, de início, chama nossa atenção, o uso dos vocábulos (06) vortou e (08) prantação, ao invés de voltou e plantação. Neles, verificamos a troca do 'l' pelo ' $\mathrm{r}$ ', o que, em termos simples, caracteriza uma alteração fonético-fonológica. De modo geral, as alterações fonéticofonológicas se realizam por meio de três processos: substituição/troca, supressão/queda e acréscimo (CÂMARA JÚNIOR, 1978). Na compreensão de Martins (2000), as alterações fonético-fonológicas são fenômenos muito presentes na obra de autores e compositores regionalistas e passam a ter valor estilístico quando "têm a função de evocar o nível cultural das personagens ou marcar a língua [...] das zonas rurais ou do sertão" (MARTINS, p. 52).

Nessa mesma linha de raciocínio, Leon (1971) explica que a matéria fônica possui valor estilístico quando remete a traços identificadores da origem geográfica, da classe social, dentre outros aspectos que compreendem a identidade sociocultural do emissor. Argumentamos que essa nos parece ser a intenção do compositor ao usar vocábulos como 'vortou' e 'prantação'. Importante dizer também que a troca do 'l' pelo 'r' (voltou vortou) é amplamente conhecido como rotacismo. Além disso, vale pontuar que o rotacismo, apesar de ser amplamente documentado em diversas variedades de fala do Português Brasileiro, ainda tende a ser associado à linguagem de sujeitos desfavorecidos socioeconomicamente e 
oriundos de algumas regiões interioranas (FREITAG et. al., 2010; BORTONI-RICARDO, 2011).

Além da troca do 'l' pelo 'r', localizamos a supressão de alguns sons no termo pro dos versos (2) Que pro norte relampeia e (6) E vortou pro meu sertão. Conhecido como síncope, esse fenômeno é linguisticamente caracterizado pela supressão de sons no segmento átono do lexema (FARIA, 1955). Apontada como um dos fenômenos mais produtivos do Português Brasileiro, a síncope, assim como o rotacismo, vem sendo registrada desde o latim vulgar (AMARAL, 1982).

Ao lado dos processos marcados por supressão como nos vocábulos (12) pr'esse, identificamos alterações caracterizadas pelo acréscimo de fonemas no início dos vocábulos, como em (10) alembrou. Em linhas gerais, esse fenômeno é denominado de prótese e consiste, justamente, na "inserção de um fonema no início da palavra" (BOTELHO; LINS, 2006).

Outro fenômeno resultante de alterações fonético-fonológicas e que se estende para o nível dos morfemas, presente na letra de $A$ volta da Asa branca, é a ausência de concordância nominal, como nos versos (13) das muié séria e (14) Dos home trabaiado. De acordo com Guimarães e Alves da Silva (2016), a língua portuguesa apresenta duas possibilidades para a realização da concordância nominal. Na primeira possibilidade, todos os elementos que compõem o sintagma nominal (SN) apresentam o morfema responsável pela marcação da noção de plural, o 's'. Em sentido oposto, a segunda realização possível da concordância nominal, ocorre sem a presença do 's' em todos os constituintes do SN, mas sim e, na grande maioria das vezes, apenas no primeiro elemento do SN, como é possível observar nos versos em destaque.

Ainda de acordo com Guimarães e Alves da Silva (2016), a segunda forma vem sendo amplamente documentada por estudos desenvolvidos à luz de diferentes vertentes teóricas na língua portuguesa. Vale ressaltar que muitos estudos sociolinguísticos, por exemplo, acerca da variação na concordância nominal, indicam que esse processo acontece com uma alta frequência em variedades pouco prestigiadas socialmente (GUIMARÃES; ALVES DA SILVA, 2016).

Identificamos ainda algumas alterações fonético-fonológicas marcadas pela supressão e mudança de alguns fonemas, como no uso do termo (17) moiada, ao invés de molhada. Conhecido como iotização, esse fenômeno é marcado pela passagem da lateral /K/ grafada como 'lh' - para /i/ e há décadas é registrado em diferentes variedades do Português 
Brasileiro, a partir de estudos desenvolvidos em diferentes perspectivas teóricas (CARUSO, 1983; ARAGÃO, 1996; BRANDÃO, 2007). Embora saibamos que é possível encontrar ocorrências, ainda que discretas, da iotização no falar de brasileiros situados em grandes centros urbanos e com alto nível de escolaridade (AMORIM; CARVALHO, 2011), Brandão (2007, p. 91) sinaliza que a iotização é um fenômeno "bastante produtivo na fala de comunidades rurais ou de grupos com baixo ou nulo nível de escolaridade".

Ao lado dos fenômenos variáveis mencionados nos parágrafos anteriores, merece destaque a insistência no uso da vogal /a/ - presente na maioria dos vocábulos que constituem a letra de $A$ volta da Asa branca. De acordo com Martins (2000), a repetição de um mesmo som vocálico em sílabas tônicas e/ou não acentuadas é denominada de assonância. Fenômeno da linguagem estilística/expressiva, assim como a aliteração, a assonância é um recurso estilístico/expressivo bastante presente em discursos poéticos e cancioneiros (MARTINS, 2000; MONTEIRO, 2009).

Além de gerar o chamado fenômeno da assonância, a insistente repetição da vogal /a/ chama atenção por ser considerada "o fonema mais sonoro, mais livre, de todo o nosso sistema fonológico" (MARTINS, 2000, p.29). Por essa razão, dentre as potencialidades estilísticas/expressivas do /a/, tem sido apontado que o uso insistente dessa vogal é capaz de realçar ideias, sentimentos de alegria, brancura, harmonia (MARTINS, 2000; MONTEIRO, 2009). Nesse sentido, pontuamos que essa nos parece ser mesmo a intenção do locutor ao explorar bem a presença da vogal /a/ na letra de A volta da Asa branca. Afinal, ao longo de toda canção, é notável o tom de celebração, alegria e esperança, sentimentos provocados pelo retorno das chuvas às secas terras do sertão, bem como a tentativa de descrever o cenário gerado por tal acontecimento.

Nesse sentido, é importante esclarecer que, naturalmente, somente a presença do /a/ não é suficiente para expressar ideias, sentimentos alegres, harmoniosos. Para isso, é necessário também que o significado dos vocábulos remetam a questões como essas, o que nos parece ser o caso de vocábulos como (16) cachoeira, (18) riqueza, (19) branca, (20) beleza, (21) alegre, (22) natureza, dentre outros. Assim, vemos que o traço estilístico dos segmentos sonoros decorre de um encontro feliz com o significado dos vocábulos. Nesse sentido:

Um ou outro dos caracteres constitutivos do fonetismo da palavra considerada deve ser a imagem de um ou outro aspecto do significado. É o sentido que serve de filtro, recusando os valores fonéticos sem relação com 
os elementos do significado e exaltando os valores concordes. Assim, o potencial de 'escuridão' da vogal /u/, [por exemplo], se aproveita em escuro, noturno, mas é recusado em luz e diurno (MARTINS, 2000, p.27, grifos no original).

Além desses, muitos outros fenômenos podem ser localizados ao longo da letra de $A$ volta da Asa branca. Sobre os fenômenos de variação linguística muito presentes na letra da canção, compreendemos que eles podem ser pensados não apenas como fenômenos variáveis, mas também e talvez principalmente como um dos recursos estilísticos mais recorrentes na obra de Luiz Gonzaga. A esse respeito, compartilhamos as ideias de Bagno (2013, p.83) quando diz que trabalhos como os de Luiz Gonzaga "não são representações fiéis das variedades que eles supostamente veiculam. Não são nem têm que ser, já que [nesse tipo de trabalho] está presente uma intenção lúdica, artística, estética e, nem de longe um trabalho científico rigoroso". Em outros termos, temos na letra de A volta de Asa branca uma tentativa de representação e não uma representação fiel das variedades linguísticas que os compositores buscam evocar.

Para o ensino de língua materna, acreditamos que refletir sobre essas questões é de grande valia para que o alunado possa compreender que muitos dos poemas, textos de autores regionalistas - muito presentes em livros didáticos - não refletem de modo fiel a imensa gama de fenômenos variáveis presentes nas mais diferentes variedades linguísticas faladas por sujeitos oriundos do interior nordestino (na grande maioria das vezes) e situados em escalas sociais não favorecidas economicamente. Assim, o caráter artístico, estilístico do uso da língua em trabalhos como em $A$ volta da Asa branca justifica o modo caricato como muitos fenômenos são abordados.

De qualquer modo, acreditamos que - com as devidas ressalvas - o trabalho com letras de canções de autores tidos como regionalistas, como Luiz Gonzaga, ajudam a promover a ideia de que nenhuma língua natural, em nosso caso específico, a Língua Portuguesa do Brasil, é um fenômeno homogêneo, mas sim um todo heterogêneo que oferece, na grande maioria da vezes, mais de uma possibilidade para dizermos a mesma coisas do ponto de vista linguística. Além disso, o tratamento das dimensões heterogênea e estilística da língua por meio de letras de canções como A volta da Asa branca abre espaço para que possamos trabalhar a ideia de língua enquanto identidade social. Sobre a dimensão heterogênea da língua e trabalhada por artista como Luiz Gonzaga, sabemos que documentos oficiais como os Parâmetros Curriculares Nacionais de Língua Portuguesa (PCNs), 
elaborados com o intuito de nortear o ensino de língua materna, além de indicarem o trabalho com o gênero letra de canção, reconhecem que:

A língua portuguesa, no Brasil, possui muitas variedades dialetais. Identificam-se geográfica e socialmente as pessoas pela forma como falam. Mas há muitos preconceitos decorrentes do valor social relativo que é atribuído aos diferentes modos de falar: é muito comum se considerarem as variedades linguísticas de menor prestígio como inferiores ou erradas (BRASIL, 1997, p. 26).

Nesse sentido, acreditamos que trabalhar em sala de aula gêneros que compreendam fenômenos de variação linguística como a letra da canção $A$ volta da Asa branca é de grande valia para promover o reconhecimento e a compreensão de diferentes fenômenos variáveis presentes na língua portuguesa. No caso da letra da canção A volta da Asa branca, nunca é demais reforçar, a importância de frisarmos o caráter artístico, estilístico como o qual o interprete da canção se vale de fenômenos como rotacismo, variação na concordância nominal, iotização - comentados anteriormente, e outros mais, presentes na letra da canção para representar traços linguísticos que podem ser verificados na linguagem espontânea, falada por determinados grupos socais. Acreditamos que essa abordagem auxilia o preparo dos estudantes para uma possível abordagem de fenômenos variáveis a partir de trabalhos científicos comprometidos com a realidade sociolinguística brasileira, como os estudos desenvolvidos no âmbito de áreas do conhecimento como a Sociolinguística de linha variacionista (WEINREICH; LABOV; HERZOG, 2006; BAGNO, 2007; LABOV, 2008).

Sobre a dimensão estilística da letra da canção $A$ volta da Asa branca, ressaltamos a maneira como Gonzaga lança mão de diferentes fenômenos variáveis para referir traços de sua identidade social, bem como elementos ligados à sua vivência, o que caracteriza aspectos ligados ao ego, conforme a compreensão de Bally (1951). Um segundo aspecto da noção de estilo proposta por Bally (1951) e que podemos verificar na obra de Gonzaga, mais especificamente, em A volta da Asa branca, é o modo como os recursos linguísticos, na figura de fenômenos de variação linguística, estão relacionados a questões sociais as quais está submetido o interprete da canção.

Sobre esse ponto, frisamos que um dos traços mais importante da obra de Luiz Gonzaga é justamente o modo como ele busca por meio das letras de suas canções, abordar problemas sociais e, talvez principalmente, exaltar traços da cultura de sua terra natal, dentre os quais a linguagem é um dos mais significativos. Esses fatos ventilam a tese de que, embora 
se trate apenas de uma tentativa de representação, alguns dos fenômenos expressivos presentes na letra da canção de Luiz Gonzaga remetem à linguagem usada por sujeitos situados em grupos desfavorecidos socioeconomicamente e oriundos de regiões interioranas.

Ademais, é pertinente dizer que as escolhas, dentre os meios de expressão, feitas por Gonzaga, e refletidas no uso de fenômenos que remetem a fenômenos de variação linguística, também caracterizam o que estudiosos como Martins (2000), Monteiro (2009) e Assis (2011) chamam de fuga da norma. Tal como procuramos destacar na seção A Estilística $e$ o fenômeno do estilo linguístico: um pouco de teoria, a fuga da norma - diga-se, 'norma padrão' - também figura como um dos meios mais produtivos para a construção do estilo estilístico em obras de autores regionalistas.

Assim, por exemplo, ao fazer uso de expressões como (14) Dos home trabaiado, ao invés de Dos homens trabalhadores, em A volta da Asa branca, Luiz Gonzaga foge, 'desobedece' às normas de concordância nominal impostas pela tradição normativa. Afinal, segundo as gramaticas tradicionais (BECHARA, 2001), na composição de um SN, os termos determinantes devem concordar, nesses casos, em número com os termos determinados. Todavia, não é isso que ocorre em $A$ volta da Asa branca.

Além desses, é possível identificar na letra da canção, conforme mostramos nos parágrafos anteriores, o uso de diversos termos e expressões que escapam à tradição normativa. Com isso, pensamos que a fuga da norma figura como mais um ponto que assinala o estilo da canção em foco.

Vale ressaltar que, conforme já mencionamos, interessa à Estilística descritiva os enunciados que apresentam finalidades estéticas fato que justifica a compreensão de desvio como oposição ao uso da norma padrão da língua. Entretanto, apenas é considerado estilístico o desvio proposital e que resulta em efeito estilístico. Ou seja, quando os desvios compreendem possíveis falhas ou inabilidade com a composição de certos enunciados tanto falados como escritos, não há aspectos estilísticos a considerar.

Acreditamos que esse não é o caso dos desvios da norma presentes em A volta da Asa branca. Na verdade, compreendemos que os desvios da norma presentes na letra da canção, ocorrem de modo intencional, haja vista o intuito, por parte dos compositores e conforme vemos discutindo ao longo deste texto, de referir traços da linguagem espontânea e usada por determinados sujeitos: situados em escalas sociais desfavorecidas economicamente, oriundos do sertão nordestino e em situações espontâneas de interação comunicativa. 
Afinal, ainda que não sejam exclusividade do falar dos referidos grupos, a frequência de uso da não concordância nominal padrão, por exemplo, é maior no falar de indivíduos com nenhuma ou pouca escolaridade (GUIMARÃES; ALVES DA SILVA, 2016). Com isso, ao abrir mão de usar apenas termos ou expressões consagradas pela tradição normativa, Luiz Gonzaga aproxima as expressões linguísticas de sua obra da norma comum, própria dos grupos sociais que buscou representar.

\section{Considerações finais}

Neste artigo, colocamos em discussão o potencial estilístico de alguns fenômenos de variação linguística presentes na letra da canção $A$ volta da Asa branca, interpretada por Luiz Gonzaga. Localizamos fenômenos variáveis como iotização, rotacismo, variação na concordância nominal, dentre outros. A partir da identificação desses fenômenos, procuramos analisar o modo como os compositores da canção procuram, não de modo fidedigno, representar traços linguísticos de variedades faladas por sujeitos oriundos do interior do sertão nordestino.

Além disso, defendemos e apresentamos algumas possibilidades de análise para o tratamento da variação linguística enquanto recurso estilístico a partir do gênero letra de canção. Vimos que, o trabalho com letras de canções de autores regionalistas possibilita, dentre outras coisas, a reflexão sobre a diversidade linguística, presente em toda e qualquer língua natural, em nosso caso específico, a Língua Portuguesa falada no Brasil.

Evidentemente, as discussões que estabelecemos ao longo deste texto não se enceram, tampouco intentamos encerá-las, aqui, dada a sua complexidade. De qualquer modo, acreditamos que com este breve estudo, deixamos valiosas contribuições para as discussões acerca da variação, estilo e seu tratamento no ensino de língua materna.

\section{Referências}

BALLY, Challes. El linguaje y la vida. Tradução de Amado Alonso. Buenos Aires: Ed. Losada, 1941.

BALLY, Challes. Traté de Stystique Français. 3. ed. Paris-Genebra: Librarie KlincksieckLibrairie Geog e Cie.,1951.

BORTONI-RICARDO, Stella Maris. Do campo para a cidade: estudo sociolinguístico de migração e redes sociais. São Paulo: Parábola Editorial, 2011. 
FARACO, Carlos Alberto; ZILLES, Anna Maria. Para conhecer norma linguística. São Paulo: Contexto, 2017.

FREITAG, Raquel Meister Ko; ARAÚJO, Andreia Silva de; BARRETO, Eccia Alécia; CARVALHO, Eliane dos Santos Silva de. Vamos prantar frores no grobo da Terra: estudando o rotacismo nas séries iniciais da rede municipal de ensino de Moita Bonita/SE. RevLet: Revista Virtual de Letras, Goiás, v. 2, n. 2, p. 17-31, 2010. Disponível em: <http://www.revlet.com.br/artigos/50.pdf>. Acesso em: 04 abr. 2019.

GUIMARÃES, Maria Aparecida de Souza; SILVA, Jorge Augusto da. Variação na Concordância Nominal de Número no Português Popular de Vitória da Conquista - BA: Sócio-História do Português do Brasil. Revista Tabuleiro das Letras, v. 10, n. 2, p. 139-151, 2016.

Disponível

em:

<https://www.revistas.uneb.br/index.php/tabuleirodeletras/article/view/3191/2066> Acesso em: 12 abr. 2019.

LEON, Pierre R. Essais de phonostylistique. Studia fonética. 4. ed. Paris: Delagrave, 1971.

MARTINS, Nilce Sant' Anna. Introdução à Estilística: a expressividade na língua portuguesa. 3. ed. rev. e num. São Paulo: T. A. Queiroz, 2000.

MONTEIRO, José Lemos. A Estilística: Manual de análise e criação do estilo literário. 2. ed. Petrópolis: Vozes, 2009.

ASSIS, Eleone Feraz de. O estilo concebido como desvio. Revista ícone, v.8, n. 1, p.81-95, 2011. Disponível em: <http://www.revista.ueg.br/index.php/icone/article/view/5084>. Acesso em 08 abr. 2019.

BRASIL, Ministério da Educação e do Desenvolvimento. Parâmetros Curriculares Nacionais de Língua Portuguesa: ensino de primeira à quarta série. Brasília-DF: MEC/SEF, 1997. Disponível em: < http://portal.mec.gov.br/seb/arquivos/pdf/livro02.pdf>. Acesso em: 07 abril. 2019.

MARCUSCHI, Luiz Antônio. Produção textual, análise de gêneros e compreensão. São Paulo: Editora Parábola, 2008.

TRAVAGLIA, Luiz Carlos. Gramática e interação: uma proposta para o ensino de gramática. São Paulo: Cortez Editora, 14 ed. 2009.

BECHARA, Evanildo. Moderna gramática portuguesa. 37. ed. Rio de Janeiro: Editora Lucerna, 2001.

AMARAL, Amadeu. O dialeto caipira: gramática: vocabulário. 4. ed. Hucitec: São Paulo: Hucitec / Brasília, 1982.

AMORIM, Gustavo da Silveira; CARVALHO, Solange Carlos de. A realização do /nh/ no falar recifense: uma análise descritiva preliminar. Sociodialeto, Campo Grande, v. 1 n. 5 p. 115 , 2011.

Disponível em: 
<http://www.sociodialeto.com.br/edicoes/10/13122011123406.pdf>. Acesso em: 07 abr. 2019.

ARAGÃO, Maria do Socorro Silva. A Despalatalização e Consequente Iotização no Falar de Fortaleza. In: Anais... XIV Jornada de Estudos Linguísticos do GELNE, Natal - RN. XIV Jornada de Estudos Linguísticos do GELNE - Resumos, p. 1-8, 1996.

BAGNO, Marcos. Sete erros aos quatro ventos: a variação linguística no ensino de português. São Paulo: Parábola Editora, 2013.

BAGNO, Marcos. Nada na língua é por acaso: por uma pedagogia da variação linguística. São Paulo: Parábola Editorial, 2007.

CÂMARA JÚNIOR. Joaquim Mattoso. Contribuições à Estilística portuguesa. Rio de Janeiro: Livro Técnico, 1978.

CARUSO, Pedro. A iotização do /-lh-/ segundo o Atlas prévio dos falares baianos. Alfa Revista de Linguística, São Paulo, v. 27, n. 2, p. 47-52, 1983. Disponível em: http://seer.fclar.unesp.br/alfa/article/view/3657/3426. Acesso em: 07 abr. 2019. 